\section{The Norman Empire}

\section{The Pagi (pays)}

I P. Pontivus, le Pontieu.

II P. Viminaus, le Vimeu.

III P. Ambianensis, l'Amiénois (Amiens).

IV P. Tellaus, le Talou.

V P. Bellovacensis, le Beauvaisis (Beauvais).

VI P. Caletus, le Pays de Caux.

VII P. Rodomensis, le Roumois (Rouen).

VIII P. Vilcassinus, le Vexin.

IX P. Parisiacus, le Parisis (Paris).

$\mathrm{X} \quad$ P. Lexovinus, le Lieuvin (Lisieux).

XI P. Ebroicinus, l'Évrecin (Évreux).

XII P. Madriacensis, le Méresais (Mérey).

XIII P. Pinciacensis, le Pincerais (Poissy).

XIV P. Durocassinus, le Drouais (Dreux).

XV P. Carnotenus, le Chartrain (Chartres).

XVI Otlinga Saxonia.

XVII P. Oximensis, l'Hiémois (Exmes).

XVIII P. Sagensis, le Séois (Séez).

XIX P. Corbonensis, le Corbonnais (Corbon).

XX P. Bajocassinus, le Bessin (Bayeux).

XXI P. Cenomanicus, le Maine (Le Mans).

XXII P. Coriovallensis (Coriallum, Cherbourg).

XXIII P. Constantinus, le Cotentin (Coutances).

XXIV P. Abrincatinus, l'Avranchin (Avranches).

XXV P. Redonicus (Rennes).

XXVI P. Aleti, le Poulet (Alet, Saint-Malo). XXVII P. Racter (?) (Dol).

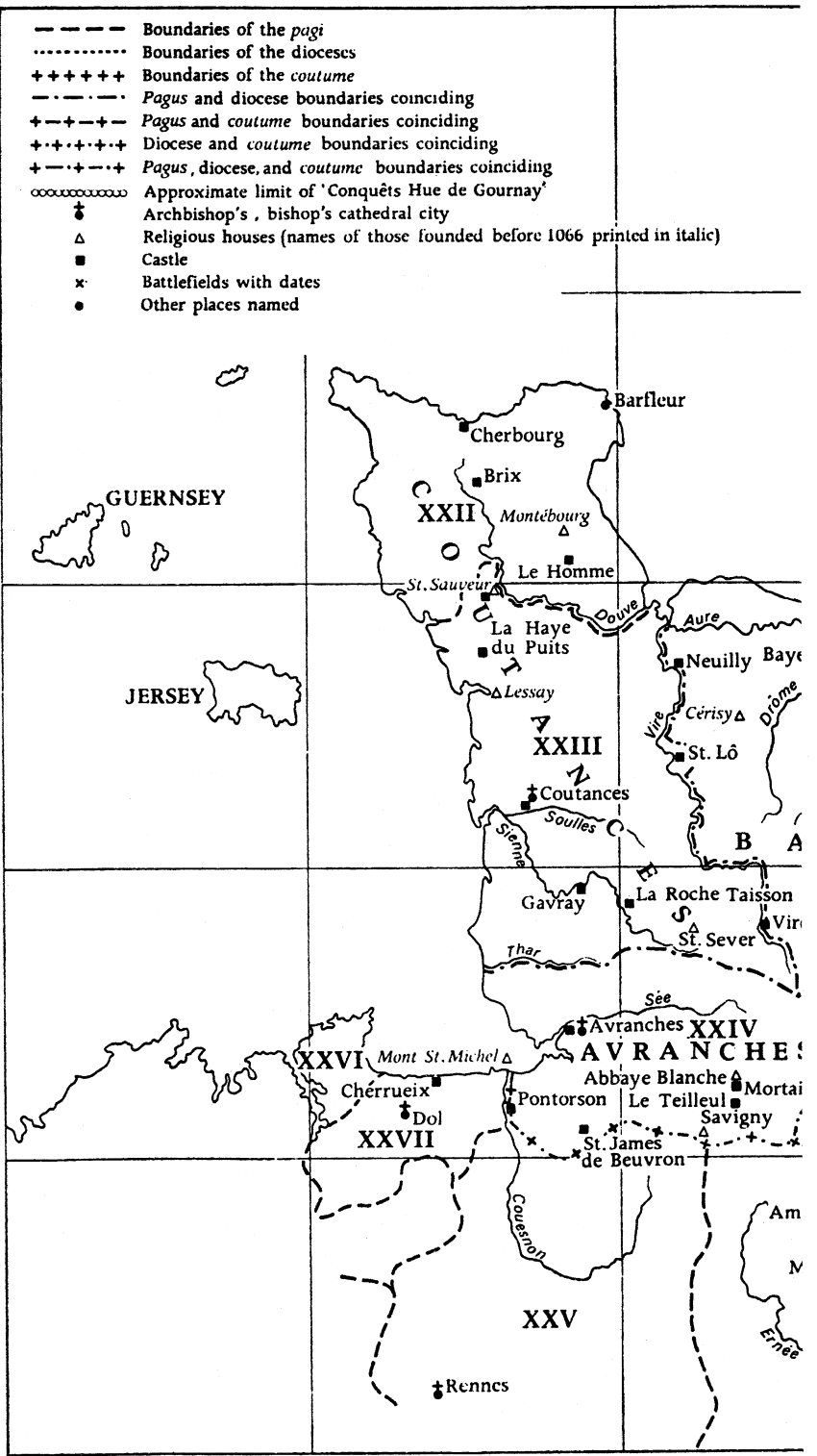




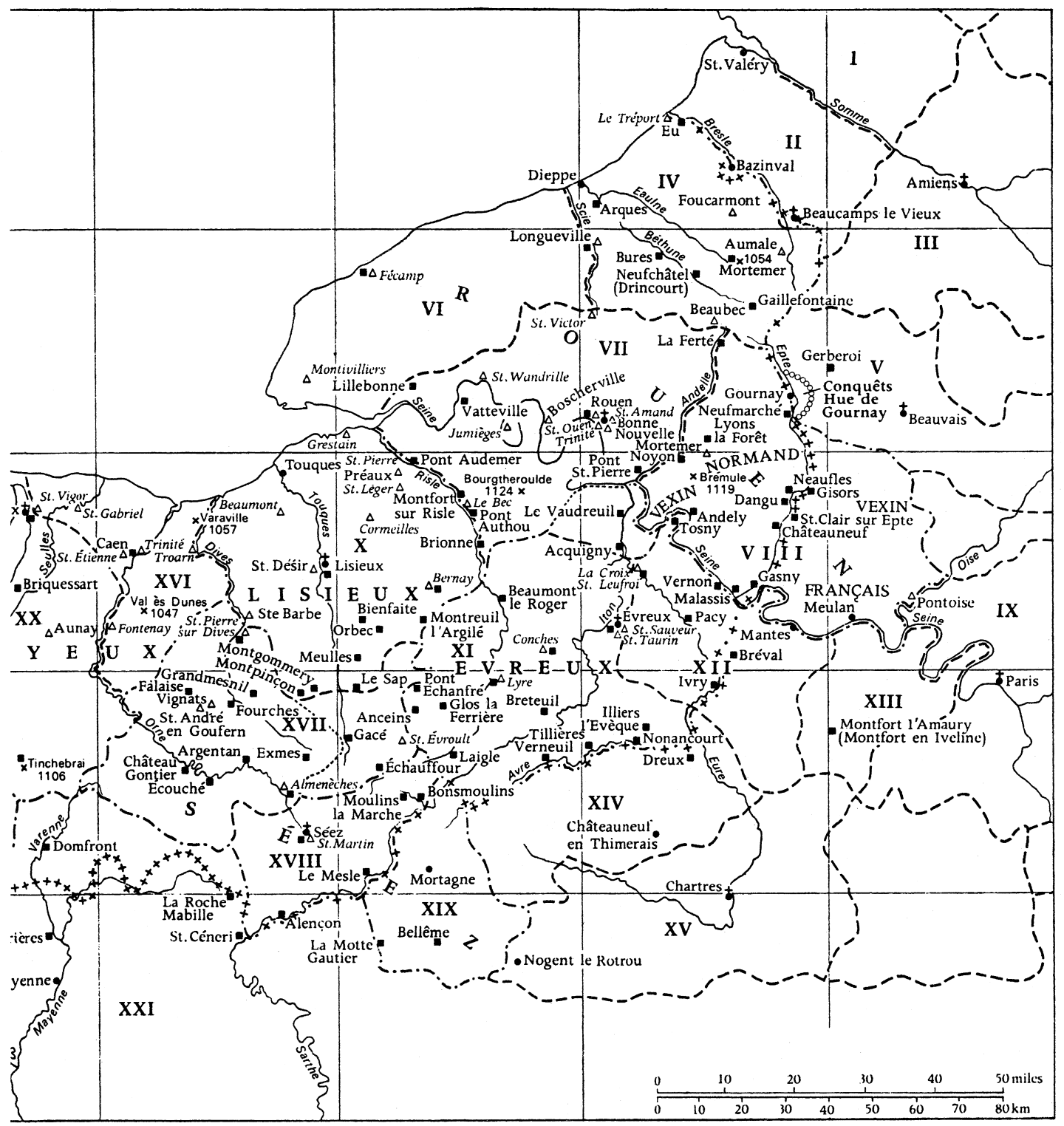

